\title{
MicroRNA-34a inhibits bladder cancer cell migration and invasion, and upregulates PTEN expression
}

\author{
ZHEN-SHAN DING ${ }^{1}$, YU-HUI HE ${ }^{2}$, YI-SEN DENG ${ }^{2}$, PAN-XIN PENG ${ }^{2}$, \\ JIAN-FENG WANG ${ }^{1}$, XING CHEN ${ }^{1}$, PEI-YU ZHAO ${ }^{1}$ and XIAO-FENG ZHOU ${ }^{1}$ \\ ${ }^{1}$ Department of Urology, China-Japan Friendship Hospital; ${ }^{2}$ Department of Urology, \\ Peking University China-Japan Friendship School of Clinical Medicine, Beijing 100029, P.R. China
}

Received August 11, 2018; Accepted February 27, 2019

DOI: $10.3892 / \mathrm{ol} .2019 .10877$

\begin{abstract}
MicroRNA-34a (miR-34a) serves as a tumor suppressor in a number of different types of cancer. The present study was performed to investigate the involvement of miR-34a in bladder cancer. In the present study, miR-34a was downregulated in patients with bladder cancer compared with the healthy controls in bladder biopsies and plasma. Downregulation of miR-34a distinguished between patients with bladder cancer and the healthy controls. miR-34a expression was associated with tumor metastasis; however, not with tumor size. Transfection of miR-34a mimics upregulated the expression of phosphatase and tensin homolog (PTEN) in bladder cancer cells, and decreased cell migration and invasion. miR-34a may inhibit bladder cancer cell migration and invasion by upregulating PTEN. miR-34a may additionally serve as a potential therapeutic target for bladder cancer.
\end{abstract}

\section{Introduction}

Tumor metastasis is a principal challenge in the treatment of cancer and it is one of the leading causes of cancer-associated mortalities $(1,2)$. Prevention and treatment of tumor metastasis is a principal task in the clinical treatment of cancer (3). Bladder cancer is the second most common malignant tumor of the genitourinary tract and it affects $>2$ million patients worldwide (4). It was predicted that the incidence of bladder cancer may significantly increase in the near future due to an increasing exposure to risk factors and an aging population (4). Treatment outcomes of patients with non-metastatic bladder cancer are generally satisfactory (5); however, survival of patients with metastatic bladder cancer remains poor (6). At

Correspondence to: Dr Xiao-Feng Zhou, Department of Urology, China-Japan Friendship Hospital, 2 Ying Hua Road, Chao Yang, Beijing 100029, P.R. China

E-mail: dzsfighting@126.com

Key words: bladder cancer, migration, invasion, microRNA-34a, phosphatase and tensin homolog present, early diagnosis and treatment are crucial for a positive prognosis.

The phosphatase and tensin homolog (PTEN) signaling pathway is a well-studied tumor suppression pathway in different types of human malignancies (7). The signaling transduction of PTEN inhibits cancer development and progression through multiple mechanisms, including promoting cancer cell apoptosis, and inhibiting cancer cell proliferation, migration and invasion (7). Activation of the PTEN signaling pathway is hypothesized to be a promising therapeutic axis for the clinical treatment of cancer (8). Inactivation of the PTEN signaling pathway, which is commonly observed during cancer development, is associated with the invasive nature of bladder cancer (9). It is frequently observed that microRNA (miRNA) interactions result in PTEN signal transduction in cancer development $(10,11)$. Expression of PTEN in hepatocellular cancer was regulated by miRNA-21 (10) and miRNA-205 directly targeted PTEN to regulate the radiotherapy resistance of human nasopharyngeal carcinoma cells (11).

miRNA-34a (miR-34a) serves as a tumor suppressor gene in different types of cancer (12). In bladder cancer, miR-34a inhibits cancer cell proliferation, migration and invasion through multiple pathways $(13,14)$. Prior to the present study, preliminary screening of bladder cancer-associated miRNAs using microarray data additionally demonstrated that miR-34a was downregulated in this disease, suggesting a possible involvement of miR-34a in bladder cancer (data not shown). In the present study, miR-34a was downregulated in bladder cancer and overexpression of miR-34a decreased the metastatic capacity of cells in vitro by activating PTEN signaling, and inhibiting cancer cell migration and invasion.

\section{Materials and methods}

Patients. A total of 172 patients were diagnosed and treated at The China-Japan Friendship Hospital (Beijing, China) between May 2015 and October 2017. The present study included 52 individuals out of these patients according to specific inclusion and exclusion criteria. The inclusion criteria were as follows: i) Patients diagnosed through bladder biopsies; ii) patients diagnosed and treated for the first time; and iii) patients willing to participate. The exclusion criteria were as follows: i) Patients complicated with other malignancies; 
ii) patients with other bladder lesions; iii) patients received treatment prior to admission; and iv) patients and/or their families refused to participate. The patients included 38 males and 14 females, age ranged between 25 and 66 years, with a mean age of $45.3 \pm 7.2$ years. At the same time, 124 individuals with suspected bladder lesions received bladder biopsies at The China-Japan Friendship Hospital. Patients with bladder lesions were excluded, resulting in 56 remaining individuals. Among these 56 individuals, 30 males and 11 females were included in the final study to match the age and sex distributions of the patient group. Bladder biopsies and plasma samples were obtained from the specimen library of The China-Japan Friendship Hospital. The present study was approved by The Ethics Committee of The China-Japan Friendship Hospital, and all patients and healthy volunteers signed informed consent.

Cell lines, cell culture and transfection. The present study included two urinary bladder cancer cell lines HT-1197 and HT-1376. The two cell lines were purchased from The American Type Culture Collection (ATCC). Cells were cultured with Eagle's minimum essential medium (EMEM; ATCC) containing $10 \%$ fetal bovine serum (FBS; Sigma-Aldrich; Merck KGaA) in an incubator at $37^{\circ} \mathrm{C}$ with $5 \% \mathrm{CO}_{2}$. MISSION ${ }^{\circledR}$ miRNA mimics hsa-miR-34a (5'-UGGCAGUGUCUUUAG CUGGUUGU-3') and MISSION ${ }^{\circledR}$ miRNA negative control 1 (5'-UGUGUGGGCAUUCUACUACACU-3') (both from Sigma-Aldrich; Merck KGaA) were transfected into $5 \times 10^{5}$ cells at a dose of $50 \mathrm{nM}$ using Lipofectamine ${ }^{\circledR} 2000$ (Invitrogen; Thermo Fisher Scientific, Inc.). Untransfected cells were used as control cells and cells transfected with negative control 1 miRNA were used as the negative control cells. Subsequent experiments were performed at $24 \mathrm{~h}$ post-transfection.

Reverse transcription quantitative-polymerase chain reaction $(R T-q P C R)$. Extraction of miRNA from biopsies and in vitro cultivated cells was performed using the miRNeasy kit (Qiagen China Co., Ltd.) under the following thermal conditions: $55^{\circ} \mathrm{C}$ for $10 \mathrm{~min}$ and $80^{\circ} \mathrm{C}$ for $10 \mathrm{~min}$. cDNA was synthesized using the miScript II RT kit (Qiagen China Co., Ltd.). miR-34a expression was detected by RT-qPCR using the miScript SYBR Green PCR kit (Qiagen China Co., Ltd.) with RNU6 miRNA as the endogenous control. The primer sequences were: miR-34a forward, 5'-TGGGCATCTCTCGCTTCATCT TCCC-3'; miR-34a reverse, 5'-GTGCTGGGGAGAGGCAGG ACAG-3'; U6 forward, 5'-TCGCTTCGGCAGCACATATAC T-3'; and U6 reverse, 5'-ACGCTTCACGAATTTGCGTGT $\mathrm{C}-3^{\prime}$. The thermocycling conditions were: $95^{\circ} \mathrm{C}$ for $55 \mathrm{sec}$, followed by 40 cycles of $95^{\circ} \mathrm{C}$ for $10 \mathrm{sec}, 55^{\circ} \mathrm{C}$ for $10 \mathrm{sec}$ and $72^{\circ} \mathrm{C}$ for $30 \mathrm{~min}$. Data quantifications were normalized using the $2^{-\Delta \Delta \mathrm{Cq}}$ method (15).

Transwell cell migration and Matrigel invasion assays. Following transfection, expression of miR-34a was detected by RT-qPCR and subsequent experiments were performed only if the rate of overexpression of miR-34a was $\geq 200 \%$. Cell migration ability was evaluated using a transwell cell migration assay kit (BD Biosciences). Cell suspensions were prepared with a final cell density of $4 \times 10^{4}$ cells $/ \mathrm{ml}$. The upper chamber was filled with $4 \times 10^{3}$ cells in $0.1 \mathrm{ml}$ cell suspension and $1 \% \mathrm{FBS}$ was added. The lower chamber was filled with EMEM supplemented with $20 \%$ FBS. Cells were cultured in an incubator at $37^{\circ} \mathrm{C}$ with $5 \% \mathrm{CO}_{2}$ for $6 \mathrm{~h}$. Membranes were collected and stained with $0.5 \%$ crystal violet (Sigma-Aldrich; Merck KGaA) at $25^{\circ} \mathrm{C}$ for $15 \mathrm{~min}$. For the invasion assays, the upper chamber membrane was pre-coated with Matrigel (EMD Millipore). Invading and migrating cells were counted using an optical microscope (Olympus Corporation; magnification, $\mathrm{x} 40$ ).

Western blotting. Radioimmunoprecipitation assay buffer (Thermo Fisher Scientific, Inc.) was used to extract the total protein from bladder cancer cells, according to the manufacturer's protocol. The protein concentration was measured using a bicinchoninic acid assay. Subsequent to denaturing, protein samples (30 $\mu \mathrm{g} /$ well) were separated by SDS-PAGE on a $10 \%$ gel and subsequently transferred to polyvinylidene fluoride membranes for blocking in 5\% skimmed milk for $2 \mathrm{~h}$ at room temperature. Rabbit anti-human primary antibodies against PTEN (1:1,000; cat. no. ab32199; Abcam) and GAPDH (1:1,000; cat. no. ab32199; Abcam) were used for an overnight incubation at $4^{\circ} \mathrm{C}$. On the following day, the membranes were incubated with goat anti-rabbit immunoglobulin G-horseradish peroxidase secondary antibody (1:1,000; cat. no. MBS435036; MyBioSource, Inc.) for $1 \mathrm{~h}$ at room temperature. Membranes were developed using enhanced chemiluminescence reagent (Sigma-Aldrich; Merck KGaA) and detected using a MYECL ${ }^{\mathrm{TM}}$ Imager (Thermo Fisher Scientific, Inc.). Data normalization was performed using ImageJ (v1.34; National Institutes of Health).

Statistical analysis. All data were analyzed using GraphPad Prism 6 (GraphPad Software, Inc.). All experiments were repeated 3 times. miR-34a expression levels were compared between patients and controls using a Mann Whitney $U$ test. Cell migration and invasion data are presented as the mean \pm standard deviation and were compared either by unpaired t-test (between two groups) or a one-way analysis of variance with a post hoc Tukey's test (among multiple groups). Associations between miR-34a expression and the clinicopathological data of the patients with bladder cancer were analyzed by a $\chi^{2}$ test. $\mathrm{P}<0.05$ was considered to indicate a statistically significant difference.

\section{Results}

miR-34a expression is significantly downregulated in patients with bladder cancer compared with healthy controls in bladder biopsies and plasma. Differential expression of specific genes between patients and healthy controls may suggest the involvement of those genes in the corresponding diseases. The expression of miR-34a in the bladder biopsies and plasma of patients with bladder cancer and healthy controls were measured. miR-34a expression was significantly downregulated in patients with bladder cancer in bladder biopsies $(\mathrm{P}<0.05$; Fig. 1A) and plasma $(\mathrm{P}<0.05$; Fig. $1 \mathrm{~B})$ compared with the healthy controls.

Downregulation of $\mathrm{miR}-34 \mathrm{a}$ distinguishes between patients with bladder cancer and healthy controls. Receiver operating characteristic curve analysis was performed to evaluate the 

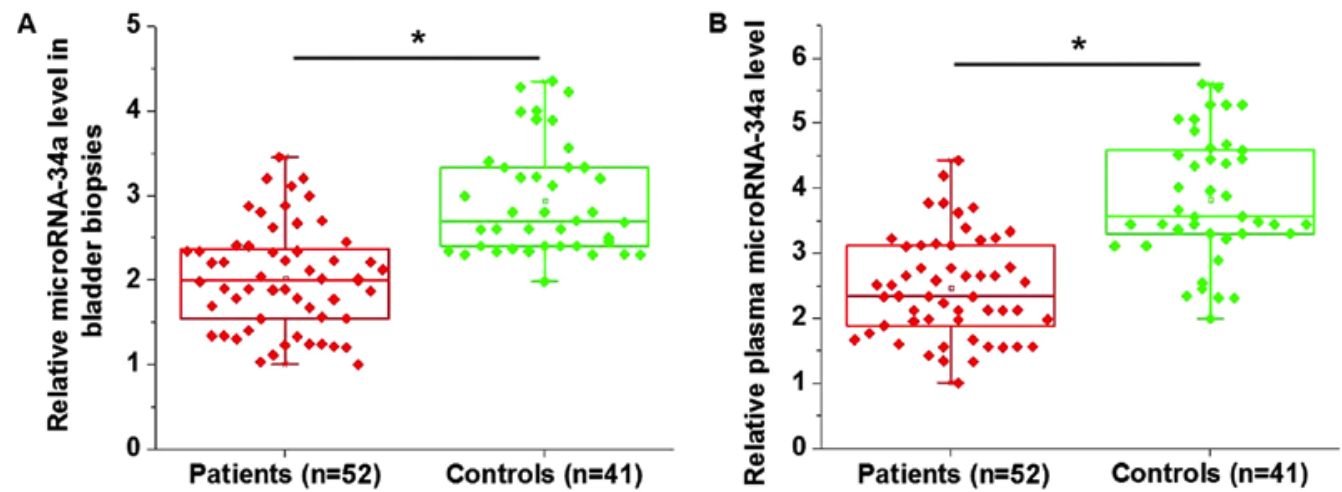

Figure 1. MicroRNA-34a expression is significantly downregulated in patients with bladder cancer compared with healthy controls in bladder biopsies and plasma. MicroRNA-34a expression in (A) bladder biopsies and (B) plasma of patients with bladder cancer and healthy controls. ${ }^{*} \mathrm{P}<0.05$.
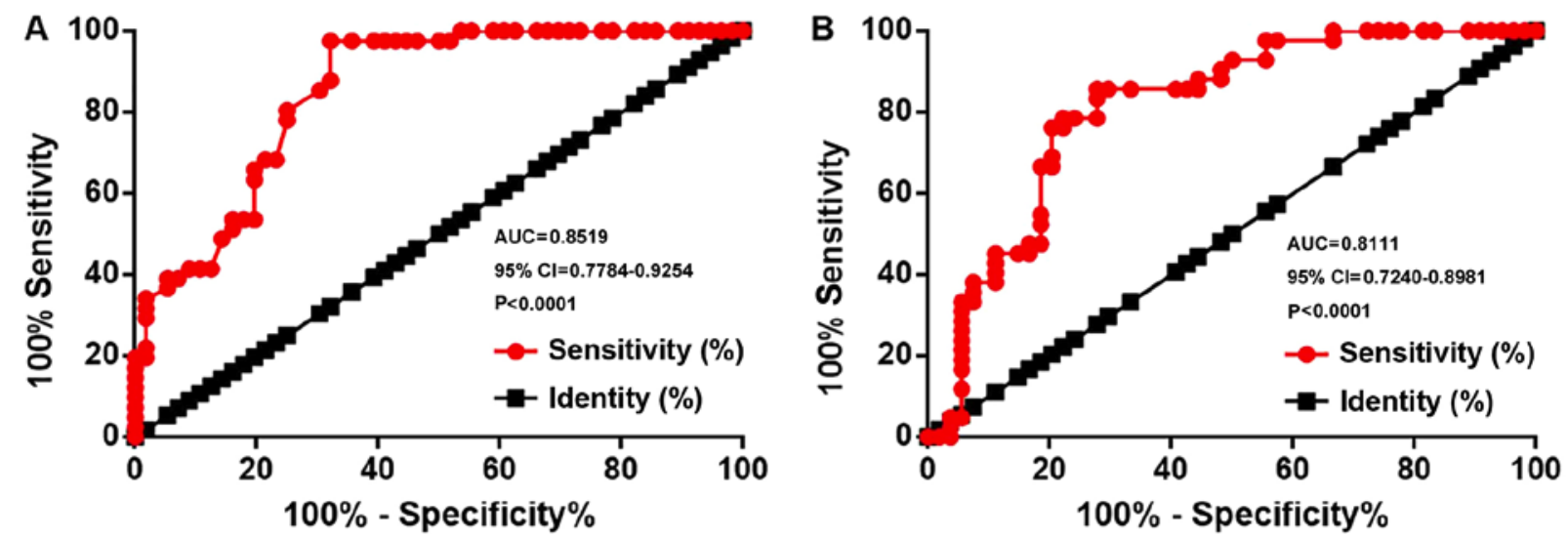

Figure 2. Downregulation of miR-34a distinguishes patients with bladder cancer from the healthy controls. Analysis of the diagnostic value of miR-34a expression in (A) bladder biopsies and (B) plasma identified miR-34a as a promising diagnostic biomarker for bladder cancer. miR-34a, microRNA-34a. AUC, area under the curve; CI, confidence interval.

diagnostic value of miR-34a expression for bladder cancer. For miR-34a expression in bladder biopsies, the area under the curve (AUC) was 0.8519 , with a standard error of 0.03748 and a 95\% confidence interval (CI) of 0.7784-0.9254 ( $\mathrm{P}<0.0001$; Fig. 2A). For plasma miR-34a, the AUC was 0.8111, with a standard error of 0.04439 and $95 \%$ CI of $0.7240-0.8981$ ( $\mathrm{P}<0.0001$; Fig. 2B).

miR-34a expression is associated with tumor metastasis; however, not with tumor size. Patients were divided into high- and low-level groups according to the median levels of miR-34a in bladder biopsies (1.99) and plasma (2.12). The associations between miR-34a expression and the clinicopathological data of patients with bladder cancer were analyzed by a $\chi^{2}$ test. The results demonstrated that miR-34a expression levels in bladder biopsies (Table I) were significantly associated with the presence of tumor metastasis $(\mathrm{P}<0.05)$. However, miR-34a expression levels were not associated with tumor size, age, sex, smoking or drinking habits.

miR-34a overexpression promotes the expression of PTEN in bladder cancer cells and promotes cell migration and invasion. The data in Tables I and II suggested that miR-34a may be involved in the metastasis of bladder cancer. Inactivation of the PTEN signaling pathway is closely associated with the invasive nature of bladder cancer (9). In the present study, miR-34a mimics were transfected into two bladder cancer cell lines, HT-1197 and HT-1376, and the effects on PTEN protein expression levels, and cell migration and invasion were determined by western blotting, transwell migration and Matrigel invasion assays, respectively. The results demonstrated that compared with the control cells and the negative control cells, cells with miR-34a overexpression demonstrated significantly upregulated miR-34a and PTEN protein expression levels $(\mathrm{P}<0.05$; Fig. 3$)$, and significantly decreased cell migration and invasion $(\mathrm{P}<0.05$; Fig. 4$)$.

\section{Discussion}

The present study demonstrated that miR-34a may serve as a tumor suppressor in bladder cancer. miR-34a may mediate tumor suppression through the upregulation of the tumor suppressor, PTEN, which may inhibit tumor cell migration and invasion.

Development of bladder cancer not only affects the local tissue environment; however, additionally globally regulates the expression levels of a larger set of genes, including miRNAs (16). At present, numerous miRNAs with altered expression patterns in bladder cancer exhibit oncogenic or 
Table I. Association between microRNA-34a expression in bladder biopsies and the clinicopathological data of patients with bladder cancer.

\begin{tabular}{|c|c|c|c|c|c|}
\hline \multirow[b]{2}{*}{ Clinicopathological characteristics } & \multirow[b]{2}{*}{ Cases } & \multicolumn{2}{|c|}{$\begin{array}{l}\text { MicroRNA-34a } \\
\text { expression }\end{array}$} & \multirow[b]{2}{*}{$\chi^{2}$} & \multirow[b]{2}{*}{ P-value } \\
\hline & & High & Low & & \\
\hline Sex & & & & 0.39 & 0.53 \\
\hline Male & 38 & 18 & 20 & & \\
\hline Female & 14 & 8 & 6 & & \\
\hline Age, years & & & & 1.23 & 0.27 \\
\hline$>45$ & 28 & 12 & 16 & & \\
\hline$\leq 45$ & 24 & 14 & 10 & & \\
\hline Smoking & & & & 0.75 & 0.39 \\
\hline Yes & 33 & 15 & 18 & & \\
\hline No & 19 & 11 & 8 & & \\
\hline Drinking & & & & 0.79 & 0.38 \\
\hline Yes & 35 & 19 & 16 & & \\
\hline No & 17 & 7 & 10 & & \\
\hline Tumor size & & & & 0.69 & 0.41 \\
\hline$>3 \mathrm{~cm}$ & 27 & 12 & 15 & & \\
\hline$\leq 3 \mathrm{~cm}$ & 25 & 14 & 11 & & \\
\hline Distant metastasis & & & & 9.43 & 0.002 \\
\hline Yes & 23 & 17 & 6 & & \\
\hline No & 29 & 9 & 20 & & \\
\hline
\end{tabular}

Table II. Association between plasma levels of microRNA-34a and the clinicopathological characteristics of patients with bladder cancer.

\begin{tabular}{|c|c|c|c|c|c|}
\hline \multirow[b]{2}{*}{ Clinicopathological characteristics } & \multirow[b]{2}{*}{ Cases } & \multicolumn{2}{|c|}{$\begin{array}{l}\text { MicroRNA-34a } \\
\text { expression }\end{array}$} & \multirow[b]{2}{*}{$\chi^{2}$} & \multirow[b]{2}{*}{ P-value } \\
\hline & & High & Low & & \\
\hline Sex & & & & 1.56 & 0.21 \\
\hline Male & 38 & 17 & 21 & & \\
\hline Female & 14 & 9 & 5 & & \\
\hline Age, years & & & & 2.79 & 0.10 \\
\hline$>45$ & 28 & 11 & 17 & & \\
\hline$\leq 45$ & 24 & 15 & 9 & & \\
\hline Smoking & & & & 0.08 & 0.77 \\
\hline Yes & 33 & 16 & 17 & & \\
\hline No & 19 & 10 & 9 & & \\
\hline Drinking & & & & 0.09 & 0.77 \\
\hline Yes & 35 & 18 & 17 & & \\
\hline No & 17 & 8 & 9 & & \\
\hline Tumor size & & & & 1.93 & 0.17 \\
\hline$>3 \mathrm{~cm}$ & 27 & 11 & 16 & & \\
\hline$\leq 3 \mathrm{~cm}$ & 25 & 15 & 10 & & \\
\hline Distant metastasis & & & & 6.31 & 0.11 \\
\hline Yes & 23 & 16 & 7 & & \\
\hline No & 29 & 10 & 19 & & \\
\hline
\end{tabular}



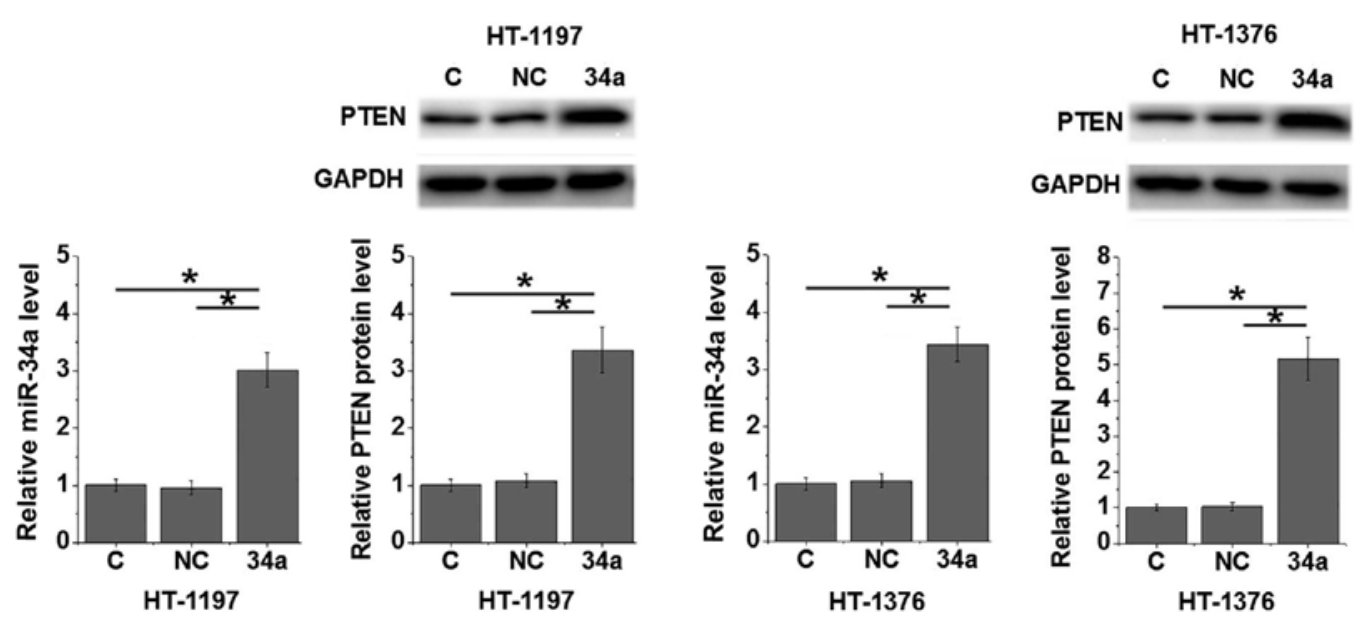

Figure 3. miR-34a overexpression promotes the expression of PTEN in bladder cancer cells. "P<0.05. miR-34a/34a, microRNA-34a; PTEN, phosphatase and tensin homolog; $\mathrm{C}$, control; $\mathrm{NC}$, negative control.
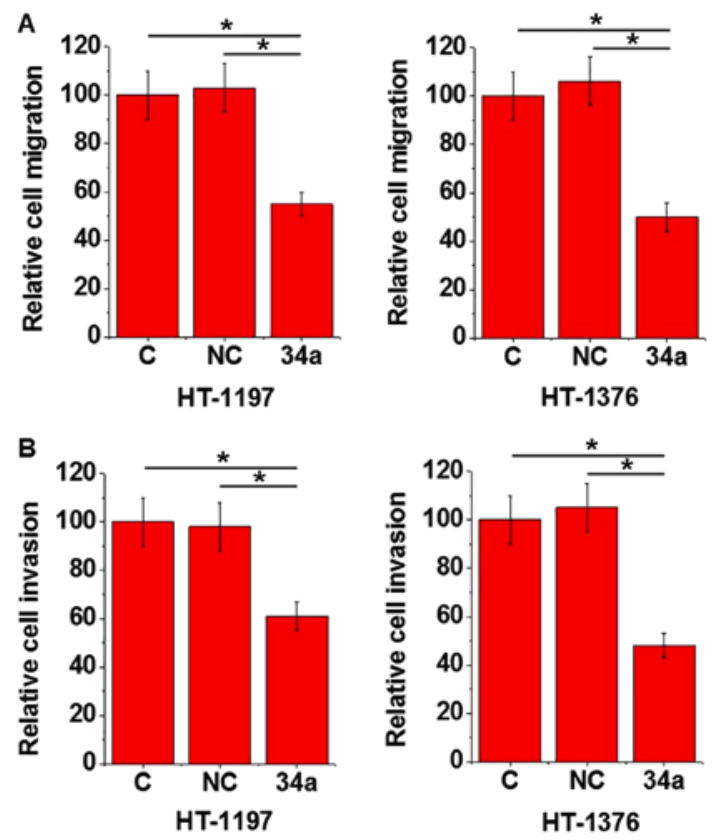

Figure 4. miR-34a overexpression inhibits cell migration and invasion of bladder cancer cell lines. miR-34a overexpression significantly increased (A) cell migration and (B) invasion. ${ }^{*} \mathrm{P}<0.05$. miR-34a/34a, microRNA-34a; C, control; NC, negative control.

tumor suppressive properties. miRNA-146a-5p expression levels were significantly upregulated in patients with bladder cancer compared with healthy individuals, and the expression level of this miRNA decreased following transurethral resection (17), suggesting a potential role as an oncogenic biomarker for bladder cancer. In contrast, miRNA-144-5p was downregulated in bladder cancer and the decreased expression level of miRNA-144-5p in patients predicted poor survival (18). miR-34a, as a tumor suppressor, is downregulated in the development and progression of a number of types of cancer, such as liver and gastric cancer (12). In the present study, miR-34a expression levels in bladder biopsies and plasma samples were downregulated in patients with bladder cancer compared with the healthy controls, suggesting a potential role of miR-34a as a tumor suppressor in bladder cancer.
Treatment outcomes of cancer at advanced stages are generally poor. At present, early diagnosis and treatment is crucial for improving the prognosis of patients with cancer. Alterations in gene expression affect the tumor microenvironment (19), and thus, may be used to guide the diagnosis of different types of cancer. In the present study, downregulation of miR-34a in bladder biopsies and plasma may be used to effectively distinguish between patients with bladder cancer and the healthy controls. miR-34a expression levels were not significantly associated with age, sex, smoking or drinking habits, which are considered influencing factors on the expression levels of certain miRNAs (20-22). Therefore, miR-34a may serve as a reliable biomarker for the detection of bladder cancer. However, miR-34a expression levels are altered in numerous types of human diseases, such as in different types of cancer, such as lung cancer and liver cancer (12). Therefore, it is preferable to use multiple biomarkers to improve the accuracy of the diagnosis.

miR-34a is involved in the regulation of tumor growth of certain types of cancer (23); however, in the present study, no significant association between miR-34a and tumor size was observed in patients with bladder cancer, suggesting the possibility of different routes of pathogenesis for different malignancies. miR-34a may be involved in the regulation of tumor metastasis due to the significant association between miR-34a expression levels and the presence of distant tumor metastasis. The in vitro cell migration and invasion assays additionally demonstrated the inhibitory effect of miR-34a on bladder cancer cell migration and invasion. PTEN signaling is involved in a tumor suppression pathway and inactivation of PTEN signaling is commonly observed in metastatic bladder cancer (9). In the present study, PTEN expression levels were significantly increased in bladder cancer cells following miR-34a overexpression. However, the mechanisms of the regulatory effects of miR-34a on PTEN or the intermediates between miR-34a and PTEN in this proposed signaling transduction pathway are unknown and require further study.

In conclusion, miR-34a is downregulated in bladder cancer and has diagnostic values. miR-34a may be involved in bladder cancer metastasis through upregulation of PTEN and inhibiting cancer cell migration and invasion. 


\section{Acknowledgements}

Not applicable.

\section{Funding}

No funding was received.

\section{Availability of data and materials}

The datasets used and/or analyzed during the current study are available from the corresponding author on reasonable request.

\section{Authors' contributions}

ZSD and XFZ designed experiments. ZSD, JFW, XC and PYZ performed experiments. YHH, YSD and PXP analyzed data. ZSD, PXP and XFZ drafted the manuscript. All authored approved this manuscriptt.

\section{Ethics approval and consent to participate}

The present study was approved by The Ethics Committee of The China-Japan Friendship Hospital (Beijing, China). All patients and healthy volunteers provided written informed consent prior to their inclusion in the study.

\section{Patient consent for publication}

Not applicable.

\section{Competing interests}

The authors declare that they have no competing interests.

\section{References}

1. Valastyan S and Weinberg RA: Tumor metastasis: Molecular insights and evolving paradigms. Cell 147: 275-292, 2011.

2. Steeg PS: Tumor metastasis: Mechanistic insights and clinical challenges. Nat Med 12: 895-904, 2006.

3. Wan L, Pantel K and Kang Y: Tumor metastasis: Moving new biological insights into the clinic. Nat Med 19: 1450-1464, 2013.

4. Ploeg M, Aben KK and Kiemeney LA: The present and future burden of urinary bladder cancer in the world. World J Urol 27 289-293, 2009

5. Marcos-Gragera R, Mallone S, Kiemeney LA, Vilardell L, Malats N, Allory Y and Sant M; EUROCARE-5 Working Group: Urinary tract cancer survival in Europe 1999-2007: Results of the population-based study EUROCARE-5. Eur J Cancer 51: 2217-2230, 2015

6. Mahmoud-Ahmed AS, Suh JH, Kupelian PA, Klein EA, Peereboom DM, Dreicer R and Barnett GH: Brain metastases from bladder carcinoma: Presentation, treatment and survival. J Urol 167: 2419-2422, 2002.

7. Jiang BH and Liu LZ: PI3K/PTEN signaling in angiogenesis and tumorigenesis. Adv Cancer Res 102: 19-65, 2009.
8. Keniry M and Parsons R: The role of PTEN signaling perturbations in cancer and in targeted therapy. Oncogene 27: 5477-5485, 2008.

9. Puzio-Kuter AM, Castillo-Martin M, Kinkade CW, Wang X, Shen TH, Matos T, Shen MM, Cordon-Cardo C and Abate-Shen C: Inactivation of p53 and Pten promotes invasive bladder cancer. Genes Dev 23: 675-680, 2009.

10. Meng F, Henson R, Wehbe-Janek H, Ghoshal K, Jacob ST and Patel T: MicroRNA-21 regulates expression of the PTEN tumor suppressor gene in human hepatocellular cancer. Gastroenterology 133: 647-658, 2007.

11. Qu C, Liang Z, Huang J, Zhao R, Su C, Wang S, Wang X, Zhang R, Lee $\mathrm{MH}$ and Yang $\mathrm{H}$ : MiR-205 determines the radioresistance of human nasopharyngeal carcinoma by directly targeting PTEN. Cell Cycle 11: 785-796, 2012.

12. Li XJ, Ren ZJ and Tang JH: MicroRNA-34a: A potential therapeutic target in human cancer. Cell Death Dis 5: e1327, 2014.

13. Sun H, Tian J, Xian W, Xie T and Yang X: miR-34a inhibits proliferation and invasion of bladder cancer cells by targeting orphan nuclear receptor HNF4G. Dis Markers 2015: 879254, 2015.

14. Zhang C, Yao Z, Zhu M, Ma X, Shi T, Li H, Wang B, Ouyang J and Zhang X: Inhibitory effects of microRNA-34a on cell migration and invasion of invasive urothelial bladder carcinoma by targeting Notch1. J Huazhong Univ Sci Technolog Med Sci 32: 375-382, 2012

15. Livak KJ and Schmittgen TD: Analysis of relative gene expression data using real-time quantitative PCR and the 2(-Delta Delta C(T)) method. Methods 25: 402-408, 2001.

16. Dyrskjøt L, Ostenfeld MS, Bramsen JB, Silahtaroglu AN, Lamy P, Ramanathan R, Fristrup N, Jensen JL, Andersen CL, Zieger K, et al: Genomic profiling of microRNAs in bladder cancer: miR-129 is associated with poor outcome and promotes cell death in vitro. Cancer Res 69: 4851-4860, 2009.

17. Sasaki H, Yoshiike M, Nozawa S, Usuba W, Katsuoka Y, Aida K, Kitajima K, Kudo H, Hoshikawa M, Yoshioka Y, et al: Expression level of urinary MicroRNA-146a-5p is increased in patients with bladder cancer and decreased in those after transurethral resection. Clin Genitourin Cancer 14: e493-e499, 2016.

18. Matsushita R, Seki N, Chiyomaru T, Inoguchi S, Ishihara T, Goto Y, Nishikawa R, Mataki H, Tatarano S, Itesako T, et al: Tumour-suppressive microRNA-144-5p directly targets CCNE1/2 as potential prognostic markers in bladder cancer. Br J Cancer 113: 282-289, 2015.

19. Wang Q, Hu B, Hu X, Kim H, Squatrito M, Scarpace L, deCarvalho AC, Lyu S, Li P, Li Y, et al: Tumor evolution of glioma-intrinsic gene expression subtypes associates with immunological changes in the microenvironment. Cancer Cell 33: 152, 2018.

20. Balaraman S, Schafer JJ, Tseng AM, Wertelecki W, Yevtushok L, Zymak-Zakutnya N, Chambers CD and Miranda RC: Plasma miRNA profiles in pregnant women predict infant outcomes following prenatal alcohol exposure. PLoS One 11: e0165081, 2016.

21. Suzuki K, Yamada H, Nagura A and Ohashi K: Association of cigarette smoking with serum microRNA expression among middle-aged Japanese adults. Fujita Med J 2: 1-5, 2016.

22. Jung HJ, Lee KP, Milholland B, Shin YJ, Kang JS, Kwon KS and Suh Y: Comprehensive miRNA profiling of skeletal muscle and serum in induced and normal mouse muscle atrophy during aging. J Gerontol A Biol Sci Med Sci 72: 1483-1491, 2017.

23. Bayraktar R, Ivan C, Bayraktar E, Kanlikilicer P, Kabil NN, Kahraman N, Mokhlis HA, Karakas D, Rodriguez-Aguayo C, Arslan A, et al: Dual suppressive effect of microRNA-34a on the FOXM1/eEF2-kinase axis regulates triple-negative breast cancer growth and invasion. Clin Cancer Res 24: 4225-4241, 2018. 